DOI: 10.2478/jbcr-2018-oO1O

\title{
INNOVATION OF AUTOMATED SYSTEMS USED IN SPREADING REGULATED INFORMATION BY ISSUERS IN THE REPUBLIC OF BULGARIA AND THE SOCIAL EFFECT ANTICIPATED
}

\author{
Yavor I. Rusinov \\ Department of Computer Sciences, \\ University of Library Studies and \\ Information Technologies - Sofia, \\ Bulgaria
}

\section{Summary}

This paper aims to demonstrate that improving automated systems used to spread regulated information has a positive social effect. The provision of capability to replace manual insertion, and particularly direct import of data in XMLformat into the systems of information agencies will save time ("economization of time") spent for spreading financial statements by $90 \%$. The saved working time can be utilized to fulfill other office tasks within current employees' obligations, carrying out office assignments not listed as present obligations. Employees could improve their qualification through familiarization with novelties in normative bases or with good practices of other companies, substitute colleagues absent from work (leave or sick leave), and analyze work environment and suggest improvements. Key words: system, XML, financial statements, spreading, saving time

\section{Introduction}

Under the Bulgarian legislation in force, issuers are companies, whose shares are issued through a initial public offering or are allowed and admitted to trade in the regulated securities market. The companies under review prefer to acquire an issuer status, because they have the opportunity and capability to get fresh capital from stock exchanges, without the obligation for direct capital return whenever shares are issued. This privilege is accompanied by a series of obligations, liabilities and responsibilities. The most important points to discuss are the disclosure of regulated information quarterly and annual financial reports spreading on a regulated market (including to investors) and a competent regulatory body.

In the Republic of Bulgaria the form, the work mode and the spread of this information by issuers are regulated by means and virtue of the Law on the Public Offering of Securities (LOPOS), "Regulation № 2 of Bulgarian Financial Supervision Commission (BFSC) for prospectuses at the public offering and admission to trade on the regulated securities market and for information disclosure" and "Rules, procedures and standards for organization, functioning and management of the unified system for provision of 
information".

Under the applicable provisions of article 100 , paragraph 3 of LOPOS, one discloses regulated information to society in a way, which secures and guarantees its announcement to the widest possible circle of interested persons simultaneously, at that in a way, which does not discriminate against them. An issuer is obliged to use and hire an information agency or another mass media, which can provide efficient spread of regulated information to society in all member countries. The above stated law requires that the important condition for the regulated information under review be disclosed electronically.

With a view to receive this information at the state regulator, the BFSC has developed, built, installed and maintains a system for transmission and receipt of the information provided by issuers. The access to the system under review is organized through a web portal supported by the Bulgarian Financial Supervision Commission, referred to as "e-register".

This paper aims to demonstrate that improving automated systems used to spread regulated information has a positive social effect.

\section{Materials and Methods}

According to the latest list of issuers [1] spread by "Bulgarian Stock Exchange - Sofia" AD, the issuers at present are 357 companies and they have announced the use of the systems of six information agencies or mass media, as listed in Table 1.

Table 1. Information agencies or mass media

\begin{tabular}{ll}
\hline FIRM NAME & Web-site \\
\hline Financial Market Service LTD, Sofia, EIK: 131455253 & www.x3news.com \\
\hline Investor.bg EIK 130277328 & www.investor.bg \\
\hline Infostock SA, EIK:203104650 & www.infostock.bg \\
\hline Web Media Grup AD, EIK: 131387286 & www.fininfo.news.bg \\
\hline BIC Capital Market Ltd, EIK: 831927223 & www.beis.bia-bg.com \\
\hline Ethic Finance, EIK: 201164403 & www.financebg.com \\
\hline
\end{tabular}

Each of these mass media is obliged to transfer the information received by the above mentioned issuers to the entry point (e-register) of BFSC, by means of which its supply to the Financial Supervision Commission is guaranteed.

The regulated market under review, on its part, under article 44, paragraph 1 of part III entitled: "Rules for Admission to Trade" of the rules for business activity, obligates the issuers to provide it with the same regulated information in an electronic way. From the above mentioned six information agencies or mass media, only Financial Market Service LTD, Sofia, has provided its subscribers by giving information to both the state regulator and to the stock exchange simultaneously. This circumstance obligates the companies using the services of the other information agencies to spread regulated information twice: first to society and, secondly, to the regulated market.

The above-mentioned law also determines a natural person, responsible for the timely dispatch of all company reports to the above- stated commission and to the regulated market, namely the Director of Investor Relations (DIR), Sofia [2]. Every company is obligated to appoint an official under permanent labor contract to this position. The access of issuers and partially of the official DIR to the systems under review is gained through identification with an electronic signature. One fills in an electronic form, which is later signed with a valid universal electronic signature. All received electronic forms and documents are stored in the databases of the above-mentioned agencies and of BFSC.

\section{Results}

Filling-in an electronic form when spreading financial information is a process, which requires manual insertion of:

- 19 digital values from the balance sheet of the company for the current reporting period;

- 9 digital values from the company's income statement for the current 
reporting period;

- 8 digital values from the company's cash flow statement under the direct method for the current reporting period;

- 19 digital values from the balance sheet of the company for a previous reporting period;

- 9 digital values from the company Income statement for a previous reporting period;

- 8 digital values from the company's cash flow statement under the direct method for a previous reporting period.

In total, 72 digital values from the relevant interim or annual (consolidated or nonconsolidated) company report are posted in the web-based application of the above-stated information agencies. After that, a desired format should be created at the entry point of the e-register, and data are to be converted into XML-format. Additional documents can be attached to the above-mentioned forms in the following formats: P7S, DOC, XLS, PDF, JPG, JPEG, GIF, TIFF, and TIF [3]. The regulator has also introduced the obligation that, regardless of the manual insertion of financial reports, the same is to be presented also in XLS-format [4]. As far as the companies, which do not draw up consolidated reports are concerned, one should stipulate that the activity for spread of this information is carried out 5 times per year. However, at companies that draw up consolidated reports, the action is completed 10 times per year.

The insertion of data in the web-based form, through their copying manually by the generated XLS-format, takes between 25 and 35 minutes, because even if there is no value in some of the fields, a " 0 " should be filled in, and the form under review requires the insertion of data not only for the current, but also for a previous period. Since input of untrue data is punishable, a check is made by the introducer to avoid mistakes. Thus, further $30 \%$ extra time is added for checking. Innovation is needed, to provide capability for replacing manual insertion, namely the direct importation of data in XML- format into the systems of the above-mentioned information agencies. Such capability would save time for the spread of financial statements to maximum 2-3 minutes, depending on the speed of an Internet connection.

At present, information agencies generate, based on manually inserted values, a file in XML-format, which they send via an encrypted communication channel to BFSC. If they receive directly a file in XML-format, they will be able to re-send it immediately to the above-stated regulator.

In order for a financial statement in XMLformat to be available at the office of the sending party, there is a need for:

- BFSC to provide publicly the XSDscheme, which is currently used by information agencies, in order to generate an XML-format file that can be imported into the database of the above-said state regulator;

- Additional adjustment of the issuers' accounting software, in order to generate the necessary file in XML-format. For the time being, they generate reports in XLS-format;

- In order for this file to arrive at the regulator, it is also necessary for the agencies to provide an opportunity for importating such files in addition to and in the forms of announcing financial reports;

- Twenty-four out of 357 issuers that operate at present, do not spread information due to falling into insolvency, going into liquidation or for other unexplored and unknown reasons. The remaining 333 business entities propagate financial reports for a period of one year, as shown in Table 2.

One hundred and twenty four companies spread information only through Financial Market Service LTD, Sofia information agency, which gives access of spread information to all statutory recipients. One hundred and fifty-seven companies spread financial information through

Table 2. Financial reports that have been propagated for a period of one year

\begin{tabular}{|c|c|c|c|c|}
\hline Quarterly reports & Annual reports & Quarterly consolidated reports & Annual consolidated reports & Total \\
\hline $333 * 4=1332$ & 333 & $118 * 4=472$ & 118 & 2210 \\
\hline
\end{tabular}


one of the remaining agencies, that provide society and the above-mentioned state regulator with access to their information and there is need for its spread again to the regulated market. Forty-five companies use, on their own free will, two agencies for data propagation, one of which is Financial Market Service LTD, Sofia, and in such case, reinsertion of data is necessary. However, seven business and legal entities have chosen to propagate data through three agencies, one of which is again Financial Market Service LTD, Sofia. Fifty-nine companies with a special investment purpose are obliged to publish their financial statements also in the e-register, because the above-mentioned state regulator has not provided an electronic form to receive messages and notifications from these companies through information agencies.

Overall, during a quarterly cycle, financial statements are spread 591 times by all companies, and further 194 times - by consolidating companies. The total of all electronic messages aiming spread of financial information by issuers is 785 items per one quarterly period. The same holds true about the number of annual reports.

For one year, one inserts messages spreading financial information, as shown in Table 3.

Table 3. Messages, spreading information for a period of one year

\begin{tabular}{lllll}
\hline \multicolumn{4}{l}{ Messages, spreading information about } & \\
\hline Quarterly reports & Annual reports & $\begin{array}{l}\text { Quarterly consolidated } \\
\text { statements }\end{array}$ & $\begin{array}{l}\text { Annual consolidated } \\
\text { statements }\end{array}$ & Total \\
\hline $608 * 4=2432$ & 608 & $194 * 4=776$ & 194 & 4010 \\
\hline
\end{tabular}

Using the average value of the time for insertion and check, i.e. $39(30+9)$ minutes and the maximmum value of time for uploading XML-files (3 minutes) we report the saved working time in minutes, if one applies the innovation, for one publication to the amount of 36 minutes in duration. The results are in Table 4.

Table 4. Messages, spreading information for a period of one year without messages from 59 items of CSIP

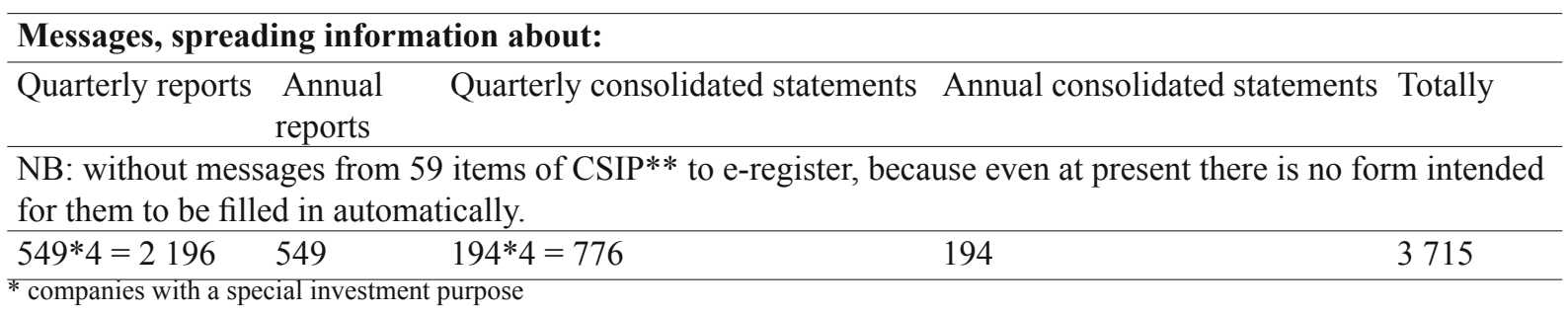

The time spent on data propagation of 3715 publications, through manual insertion adds up to 144885 minutes. The time for the distribution of 3715 publications, through automated insertion is 11145 minutes. The working time spent, expressed in an absolute value is 133740 minutes. Given in a relative value, the spent working time is $92.3 \%$.

The saved working time for one year, that is from 3715 publications, is 133740 minutes. This is 2229 hours - approximately 279 days, in the conditions of an eight-hour working day.

Therefore, if messages are spread through manual insertion by one person, it would take quite long - about 302 working days. There are 249 working days during year 2018, and if one deducts only statutory paid annual leave of 20 working days, the result is 229 working days. It means that the publication of financial reports would take an employee more than one working year. If the automated method with the attachment of XML-files is applied, this business activity would take a person about 23 working days, which is equal to one working month. This option will ensure utilization of nearly 206 working days from this year (249-20-23) for some other business activity.

Under provisions of article $116 \mathrm{~d}$ of LOPOS, every company is obliged to appoint DIR under employment contract and respectively these 
saved 279 working days per year are allocated to 333 employees, namely.

Per one DIR, whose company does not consolidate for a year that is 215 employees by 296.76 minutes (4.95 hours). Per one DIR, whose company consolidates for a year that is 118 employees by 592.69 minutes ( 9.88 hours).

\section{Discussion}

In the 70's and 80 's the discussion on the social effects of automation made the conclusion that information technology has little deterministic effects on Quality of Working Life (QWL). Positive or negative effects on QWL mainly depend on the combination with the various dimensions of the socio-technical system (organization, people, processes, management rules, etc.). Improvement of QWL is still a big challenge in modern organizations based on information technologies (IT) [5].

Automation delivers improved and effective way of doing specific tasks but automation will take time to replace the human cognitive skills for critical thinking. This means that creativity is facilitated through automation but requires human interaction.

Ethical aspects of automation revealed several concerns such as inability to make ethical decisions, accountability of medical related decisions, and lack of human feelings.

It was observed that many life cycle analysis (LCA) studies do not exist on automation. Researchers should be encouraged to study the environmental effect of automation technologies through LCA analysis to better understand the environmental impact [6].

\section{Conclusions}

The economized working time can be utilized for:

- Fulfillment of other office tasks, falling within an employee's obligations;

- Carrying-out of office assignments, not falling within the present obligations of the above-mentioned employee;

- Improvement in one's qualification through familiarization with novelties in normative basis or with the good practices of other companies;
- Substitution of a colleague s absent from work (leave or sick leave);

- Analysis of work environment and suggestions for its improvement.

The effect of the innovation under review will not lead to negative consequences, e.g. staff reduction for employees hired at present, because:

- The requirement for the appointment of an official, holding the office of DIR is statutorily given;

- The obligations of DIR include also many other activities, which the official should continue to carry out;

- There will be a necessity for temporary employment of a software developer (an IT-specialist) to automate the system under review.

\section{Acknowledgements}

There is no financial support for this research.

\section{References}

1. Bulgarian Stock Exchange - Sofia AD [Internet]. [List of issuers and the media which disclose regulated information as of 20.11.2017]. 2017 [cited 2018 March 27] Available from: http://download.bse-sofia.bg/pdf/Emitents_ Media 20112017 bg.pdf. Bulgarian.

2. Law on the Public Offering of Securities of Jan, 31, 2000. Published by Bulgarian Parliament. State Gazette. 2018 Mar 16.

3. Financial Market Service LTD, Sofia [Internet]. [Electronic system for disclosure of information]. 2007 [cited 2018 Apr 12]. Available from: www. extri.bg/tools/RulesElementsAndFormsInExtri. pdf. Bulgarian.

4. Financial Supervision Commission [Internet]. [Instructions on the sending of financial statement reports sample forms determined by the Vice Chairperson of the Financial Supervision Commission]. 2012 [cited 2018 May 30] Available from: $w w w . f s c . b g / d . p h p ? i d=12520$. Bulgarian.

5. Butera F. Human oriented management of change. A conceptual model. Advances in Human Factors/ Ergonomics. 1995;20:1003-10.

6. Nouzil I, Raza A, Pervaiz S. Social aspects of automation: Some critical insights. ICMIM. 2017;244:1-9. 